\title{
Surface modification of polyaniline nanofiber using silver nanoparticles to enhance sensing properties
}

\author{
Yasir Ali ${ }^{1 *}$, Vijay Kumar ${ }^{1}$, A.S. Dhaliwal ${ }^{1}$, R.G. Sonkawade ${ }^{2}$ \\ ${ }^{1}$ Department of Physics, Sant Longowal Institute of Engineering and Technology, Longowal (Sangrur) 148106, Punjab, India \\ ${ }^{2}$ School of Physical Sciences, BBA University (A Central University), Lucknow 226025, India
}

"Corresponding author. E-mail: yasirali876@gmail.com

Received: 06 September 2012, Revised: 09 October 2012 and Accepted: 17 October 2012

\section{ABSTRACT}

The surface of polyaniline nanofibres is modified by silver nano particles using cyclic voltametry (CV). The surface modifications induced by silver particles are confirmed by scanning electron microscopy (SEM), Energy dispersive X-ray analysis (EDX) and Raman spectroscopic techniques. The SEM micrographs show uniform distribution of silver particles on the surface of PANI nano fibers. Presence of silver particles was confirmed by EDX. Structural variations induced after reduction of Ag-metal particles and formation of polaron and bipolarons are studied by Raman spectroscopy. Copyright (C) 2013 VBRI press.

Keywords: Polyanniline nano fibre; silver-nitrate; cyclic-voltametry; SEM, Raman.
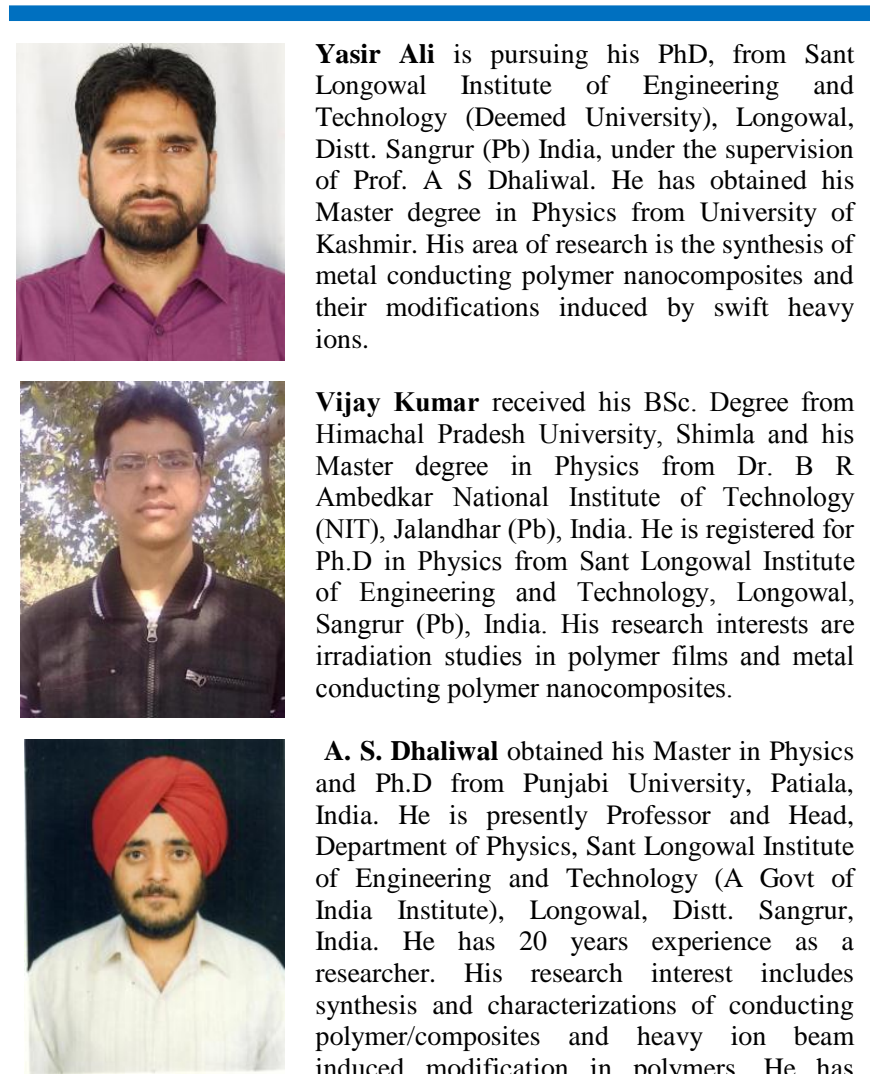

published a number and presented papers at national and international conferences.

\section{Introduction}

The combination of noble metals and conducting polymers opens new horizons of hope for researchers to overcome with challenges of day to day life. The composites of metals and conducting polymers are attention grabbing materials due to their demanding potential applications in the domain of various fields, such as chemical sensors, catalytic activities, bio-technology and micro-electronics [1-4]. Many efforts are applied for the preparation of metalpolymer composites (MPCs), such as MPC - nanostructure, MPC core-shell nano particles and MPC co-axial nano cables [5-8]. Sreeram et al. [9] have reported that conducting polymer -metal nanoparticle bulk composites provide enhanced sensitivity and selectivity for gas sensing as compared to pure conducting polymers. Coupling of metal particles with the conducting polymers offers strong electronic interaction between them which invokes researches to study these composites in detail. Therefore, this work deals with the synthesis process for the fabrication of metal polymer nanocomposite to be used for sensing application.

Among all the conducting polymers, polyaniline (PANI) has attracted great attention because of its easy synthesis process, environmental stability, light weight, conductivity, mechanical flexibility and low cost. Synthesis and characterization of polyaniline grafted with different materials using ecofriendly new approaches are adopted for sensing applications [10-17]. PANI has three distinct 
oxidation states with different colours and has an acid/base doping response [18-20]. On the other hand, silver being the most conducting among noble metals. Its unique electronic and optical properties with high conductivity and stability make it versatile material to be employed for the fabrication of composites with polymers [21-22].

To produce high quality composites with higher conductivity, the oxidation of PANI with silver nitrate solution in different acids, such as nitric, acetic, formic and sulphonic acids are reported by various researchers [23-26]. Various chemical and electrochemical methods are employed for the synthesis of Ag-PANI composite films which includes in situ photo-redox mechanism [27] and one pot synthesis method [28-29]. Shengyu et al. [30] reported the synthesis of Ag-PANI core-shell nanocomposite. Jaroslav et al. [31] reported PANI nano tubes as substrate for the reduction of silver nitrate to synthesized Ag-PANI composite. According to them the composite film exhibited the conductivity of the order of $68.5 \mathrm{Scm}^{-1}$. Dipali et al. [32] investigated Ag-PANI composites for electrochemical Supercapacitor application. Ugarte et al. [33] fabricated Ag-PANI composites through a two phase water/toluene interfacial reaction. They further mentioned that by controlling the reaction time, different structure of composites can be obtained. Recently, the extraordinary advances in the generation of new materials based on both fundamental elements and composites and their synthesis processes are reported in the literature [34]. Various authors have reported the fabrication of sensors based on the metal-oxide/PANI nanocomposite [35-37].

In previous communication, fabrication of PANI nanofibres was reported using chronopotentiometry with optimised process parameters on conducting ITO substrate [38]. Therefore, in the communication as synthesised PANI nano-fibre film is used as working electrode in the three compartment electrochemical cell for the surface modification by noble Ag-metal particles. During cyclic voltametry the reaction process was cycled for less sweep segments with moderate scan rate to have uniform distribution of Ag-particles on the surface of PANI fibers. $\mathrm{CV}$ is most appropriate technique for the surface modification of polymer films by metal particles due to the redox process. The SEM, EDAX and RAMAN spectroscopy are carried out to study modification after the reduction of $\mathrm{Ag}$ metal particles on the surface of PANI nanofiber.

\section{Experimental}

All chemicals used for the experiment were of GR grade. Aniline monomer (MERCK, 99.5\% purity) was double distilled prior to synthesis, $\mathrm{H}_{2} \mathrm{SO}_{4}$ and $\mathrm{HNO}_{3}$ (MERCK, $>99 \%$ purity), and $\mathrm{AgNO}_{3}$ (Sigma Aldrich) were used in the present investigation. For all purposes double distilled water was used.

An aqueous solution $(80 \mathrm{ml})$ of aniline and $\mathrm{H}_{2} \mathrm{SO} 4$ as a supporting electrolyte was prepared in 0.1:0.5 molar (M) concentration ratio in double deionised (DID) water for the synthesis of polyanniline nanofiber films using chronopotentiometry. The as synthesized film was later used as working electrode for surface decoration by $\mathrm{Ag}$ metals in an $80 \mathrm{ml}$ aqueous solution of $\mathrm{AgNO}_{3}$ and $\mathrm{HNO}_{3}$ in the ratio of 0.0004:0.005 $\mathrm{M}$ using $\mathrm{CV}$ technique. The electro-chemical process was carried out with CHI 660C electrochemical workstation. The standard three electrode setup was employed in one compartment electrochemical cell. A rectangular ITO sheet of size $20 \times 10 \times 0.8 \mathrm{~mm}$ was used as working electrode whereas a platinum sheet of size $20 \times 40 \times 0.25 \mathrm{~mm}$ was used as a counter electrode. The reference electrode was an $\mathrm{Ag} / \mathrm{AgCl}$ electrode. The SEM micrographs and EDX analysis were obtained using JSM6490LV Joel. The image resolution was set at 5,000X and $10,000 X$. The Raman spectroscopy is performed by a micro-Raman Spectrophotometer in the range of 500 to $2000 \mathrm{~cm}^{-1}$ at room temperature. An argon laser is used as an excitation source with an excitation wavelength of 514.4 $\mathrm{nm}$.

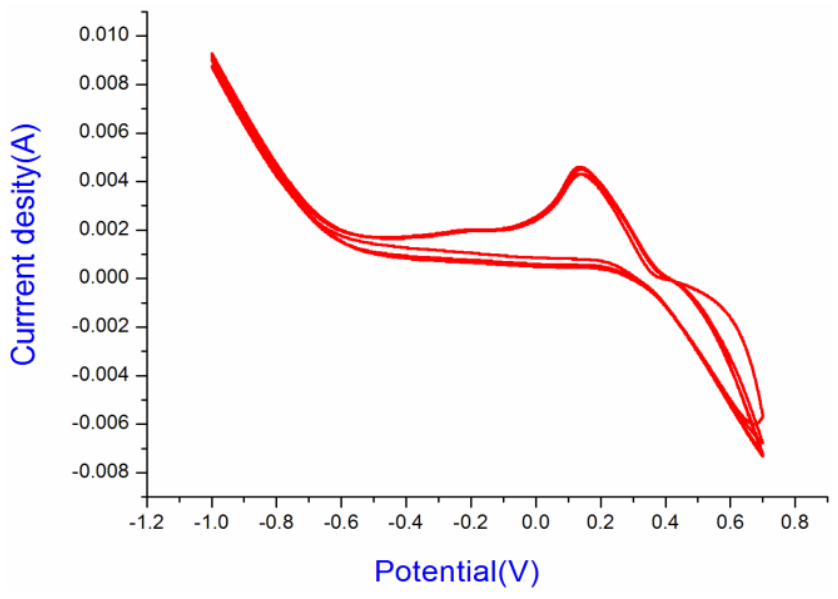

Fig. 1. The cyclicvoltragram shows of deposition of Ag particles on PANI nano fiber between potential window of $-1 \mathrm{~V}$ to $0.7 \mathrm{~V}$ in a solution of $\mathrm{AgNO}_{3}+\mathrm{HNO}_{3}$ in a ratio 0.0004:0.005 respectively with scan rate of $40 \mathrm{mV} / \mathrm{sec}$.

\section{Results and discussion}

\section{Electrochemical synthesis and characterization}

Chronopotentiometric fabrication of PANI nano-fibre was carried in as solution of 0.1:0.5 molar (M) ratio concentration of aniline and $\mathrm{H}_{2} \mathrm{SO}_{4}$ respectively with optimised process parameters as communicated earlier [38]. This technique is most sophisticated and it is reported that chronopotentiometric deposition of polymer film could produce highest electrochemical reactivity in comparison to $\mathrm{CV}$ and potentiostatic deposition methods [39]. CV is a very accepted technique which represents the electrochemical spectrum designates the potential at which number of process happen can be achieved rapidly. The working electrode i.e. PANI nano fibre was cycled using $\mathrm{CV}$ between the applied potential window ranges from -1 to $0.7 \mathrm{~V}$ at the scan rate of $40 \mathrm{mV} / \mathrm{s}$ in a solution of nitric acid contain $\mathrm{AgNO}_{3}$ for surface modification of PANI nano fibre composites as show in Fig. 1. The voltammogram is a display of current (vertical axis) verses potential (horizontal axis). The scan rate was kept at $40 \mathrm{mV} / \mathrm{sec}$ which significantly affects the role of kinetics of chemical species during the redox process. The cathodic peak shows light upgrading of peak after each cycle indicates the moment of $\mathrm{Ag}+$ cations towards the cathode i.e. PANI nano fibre electrode. The peak at 0.13 becomes more prominent shows the $\mathrm{Ag}^{+}$ions are reduced on the on the PANI nano-fiber 
after first order dissociation of $\mathrm{AgNO}_{3}$ in acidic solution of $\mathrm{HNO}_{3}$. The colour of PANI film turned faint brown like grey spots are sputtered on green polyanniline nano fiber which indicates the reduction of $\mathrm{Ag}^{+}$cations on the working electrode. The increasing current in the cathodic peak shows the growth of $\mathrm{Ag}^{+}$on the polymer surface which is also visible in the given cyclicvoltragram. The PANI nanofibres in an acidic aqueous solution can undergo an oxidative decomposition reaction leading to the removal of hydrogen and subsequent coupling of silver nano particles on the surface of polymer.

\section{Scanning electron microscopy}

The surface morphology judgment of the Ag-PANI nanofibre composite was carried out by scanning electron microscope as shown in Fig. 2 (A-B). The fibrous surface with uniformly Ag-metal particles distributed over whole surface is observed in the SEM micro graphs. Fig. 2 (B) is the magnified image which clearly displays the fibrous PANI structure and Ag-metal particles are seen as white spots on the surface of polymer film which clearly indicates their coupling with PANI nanofibers. The surface also exhibits uniform porosity in their structures which is an important factor for sensing application. Controlled and optimised process parameters are essential requirements to obtain desired results.
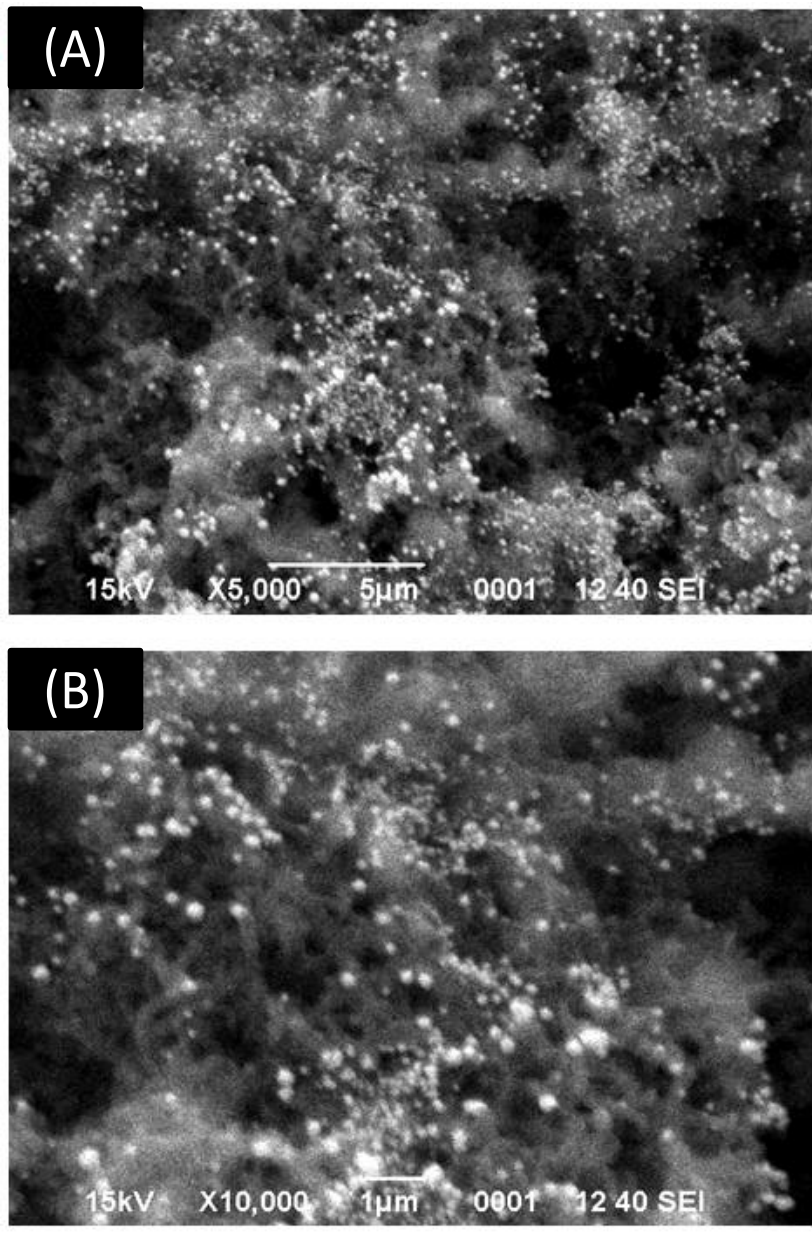

Fig. 2. SEM micrograph (A) Ag-PANI nano fiber composite (B) magnified image of (A)
After a range of permutations of process parameters, optimised scan rate and sweep segments for proper and uniform reduction of Ag-metal particles was achieved to decorate uniformly the polymer film to obtain Ag-PANI nanofibre composites. Moreover, the image shows homogeneous nucleation and high porosity, which indicate its reliability using as a sensing material. The dense network of PANI fibers and Ag-metals particles also ensures their proper redox process which enhances the stability, mechanical, optical and electrical properties of the of Ag-PANI composite. Fig. 2 shows fibrous cotton like structure.

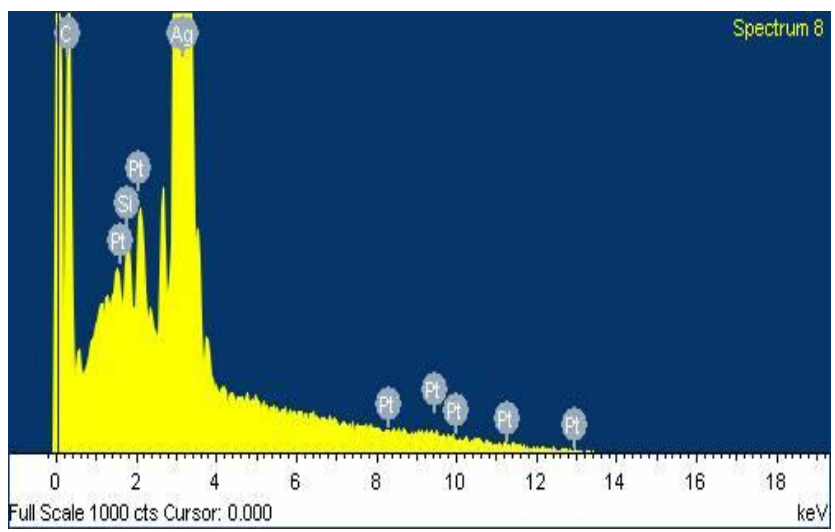

Fig. 3. EDX spectrum of silver particle on Ag-PANI nano fiber composite film.

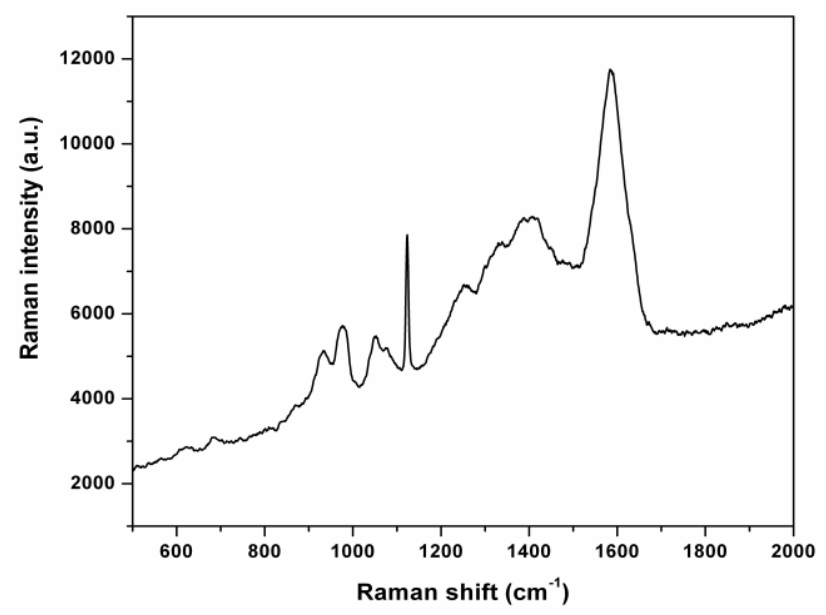

Fig. 4. Raman spectrum of Ag-PANI nano fiber composite.

\section{Energy dispersive $X$-ray analysis}

The EDX study reveals the presence of silver particles (Fig. 3). The EDX pattern shows the peak of carbon and silver (Ag). The presence of Ag-peak strongly indicates that Agparticles are successfully decorated on the PANI nanofiber. This EDX graph was taken in a complete area of millimetre range to guarantee the uniform distribution of Ag-particles on the surface polyaniline nano fibre.

\section{Raman spectroscopy}

Raman spectroscopic analysis was carried out to characterize the Ag-PANI nanofiber (Fig. 4). The characteristics of main Raman bands of the Ag-pain nano 
fiber are observed at, 1053, 1123, 1250, 1404, 1585 and $1710 \mathrm{~cm}^{-1}$. Surface modification by Ag-metal particles using CV method shows the shift, appearance and disappearance of peaks which clearly indicates that redox process has occurred between the Ag-metal particles and PANI nanofibers. This breaking and formation of bonds ensures the coupling of Ag-particles on the surface of polymer to modify its functional properties. The peak $1584 \mathrm{~cm}^{-1}$ shows the formation of semiquinone radical cation i.e. p-disubstituted benzene rings begins to transfer in to polarons [40]. The Raman spectrum peak at $1710 \mathrm{~cm}^{-1}$ shows the existence of $\mathrm{C}=\mathrm{O}$. The strong bond at $1250 \mathrm{~cm}^{-1}$ appears related to the $\mathrm{C}-\mathrm{N}^{+}$stretching of the semi-quinone radical of the emeraldine salt, this state of PANI film is treated as most conductive state [41]. The peak located at $1123 \mathrm{~cm}^{-1}$ exhibits the $\mathrm{C}-\mathrm{H}$ ring in plane bending modes of quinoid units [42]. The peak at $1404 \mathrm{~cm}^{-1}$ represents the $\mathrm{C}$ $\mathrm{C}$ stretching of quinoid units [43]. The peak at $1053 \mathrm{~cm}^{-1}$ shows the Ring vibration for ortho-disubstituted benzene. From Raman spectra it is observed that the shifts in the Raman bands occur in case of Ag-PANI nano fiber when compared with pure PANI nano fiber which is due to the insertion of Ag-metal particles on the surface of PANI fiber film. Raman shows that after the first sweep segment of CV at given scan rate, the free radical cations are produced due to removal of electrons form the amines group causes the formation of polarons and bipolarons [40].

\section{Conclusions}

Ag-PANI nano fiber composites were synthesised using two steps electrochemical method with optimised process parameters. The surface of PANI nanofiber was decorated by Ag-metal particles using CV. The presence of Ag-metal particles on the polymer surface shows redox activity between metal and polymer, which is also confirmed by Raman analysis. The SEM micrograph shows that the composite surface is uniformly modified by $\mathrm{Ag}$ metal particles which results favourable fabrication of Ag-PANI nano fiber composites. Micrographs clearly show porous and fibrous structure of polymer film. Raman describes the significant effects of polaron and bi polaron formation. Raman peak shows the emeraldine salt state of PANI nanofiber. This is simple and cost effective method for fabrication of metal-polymer nano composites.

\section{Acknowledgements}

Financial help in terms of institute fellowship by MHRD, New Delhi to Yasir Ali highly acknowledged. Our special thanks are due to Dr. S. P. Lochab for providing lab facilities.

\section{Reference}

1. Stejskal, J.; Sapurina, I.; Trchová, M. Pro Polym. Sci 2010, 35, 1420. DOI: $\frac{10.1016 / j . p r o g p o l y m s c i .2010 .07 .006}{}$

2. Della Pina, C.; Falletta, E.; Rossi, M. Catalysis Today 2011,160, 11 27.

DOI: $10.1016 /$ j.cattod.2010.05.023

3. Drelinkiewicz, A.; Zieba, A.; Sobczak, J, W.; Bonarowska, M.; Karpinski, Z.; Waksmundzka- Góra, A. Rea. \& Fun Poly 2009, 69,630 .

DOI: $10.1016 / \mathrm{j}$. reactfunctpolym.2009.04.007

4. Lenhart, N.; Crowley, K.;Killard, AJ.; Smyth, MR.; Morrin, A. Thin Solid Films 2011,519,4351.

DOI: $10.1016 /$ j.tsf.2011.02.045

5. Xing, SX. ; Zhao, GK. Mat Lett 2007, 61, 2040. DOI: $10.1016 /$ j.matlet.2006.08.011
6. Wang, SB.; Shi, GQ.Mater Chem. Phys 2007,102,255

DOI: $10.1016 /$ j.matchemphys.2006.12.014.

7. Liu YC, Chuang TC. J Phys Chem B 2003,107,383. DOI: $10.1017 /$ S0953756203237679,

8. Jing, SY. ; Xing, SX. ; Yu, LX. ; Zhao, C. Mater Lett 2007,61,4528 DOI: $10.1016 /$ j.matlet.2007.02.045,

9. Vaddiraju, S.; Gleason, K. Nanotechnology 2010, 21, 125503 DOI: $10.1088 / 0957-4484 / 21 / 12 / 125503$

10. Tiwari, A.; Singh, V. Carbohydrate Polymers 2008, 74,427 DOI: $10.1016 /$ j.carbpol.2008.03.015

11. Tiwari, A.; Singh, V . eXPRESS Polymer Letters 2007,1,308 DOI: $10.3144 /$ expresspolymlett.2007.44

12. Tiwari, A; Gong, S. Electroanalysis $2008,20,1775$ DOI: $10.1002 /$ elan.200804237

13. Tiwari, A. Journal of Macromolecular Science, Part A: Pure and Applied Chemistry 2007, 44, 735 DOI: $10.1080 / 10601320701353116$

14. Tiwari, A.; Kumar, R.; Prabaharan, M.; Ravi, R. P.; Premlata, M.; Anurag, C.; Mishra, A. K. Polymers for Advanced Technologies 2010, 21, 615. DOI: $10.1002 /$ pat. 1470

15. Tiwari, A. ; Sen V.; Dhakate, S. R.; ${ }^{1}$, Mishra, A. P.; Singh V. Polymers for Advanced Technologies 2008, 19, 909 DOI: $\underline{10.1002 / \text { pat. } 1058}$

16. Tiwari, A.; Singh, S. P. Journal of Applied Polymer Science $2008,108,1169$

DOI: $10.1002 / a p p .27789$

17. Tiwari, A. J Polym Res 2008, 15,337 DOI $10.1007 / \mathrm{s} 10965-008-9176-4$

18. Shukla, S.K. ; Bharadvaja, A. ; Tiwari, A. Parashar, G.K. ; Dubey G.C. Adv. Mat. Lett. 2010, 1, 129 DOI: 10.5185 /amlett.2010.3105

19. Simon, P.; Gogotsi, Y. Nature Materials 2008, 7, 845. DOI: $\underline{10.1038 / \mathrm{nmat} 2297}$

20. Saxena, V.; Malhotra, B. D. Current Applied Physics 2003, 293 DOI: $10.1016 /$ S1567-1739(02)00217-1

21. Zhao, C.; Zhao, Q.; Zhao, Q. ; Qiu, J.; Zhu,C.; Guo, S. J.photo.chem. DOI: $10.1016 /$ j.jphotochem.2006.10.006.

22. Deronzier, A.; Moutet, J.C. Acc. Chem. Res. 1989, 22, 249. DOI: $10.1021 / \mathrm{ar} 00163 \mathrm{a} 004$

23. Bober, P.; Stejskal, J.; Trchová, M. ; Hromadková, J.; Proke,j. Reac. \& Func.polym. 2010, 70,656 DOI: $10.1016 /$ j.reactfunctpolym.2010.05.009

24. Blinova NV, Bober P, Hromádková J, Trchová M, Stejskal J, Proke_s J. Polymer International 2010, 59, 437

25. Blinova, NV. Stejskal, J.; Trchová, M.; Sapurina, I.; Gordana, CM. Polymer 2009, 50, 50. DOI: $10.1016 / \mathrm{j}$. polymer.2008.10.040,

26. Bober, P.; Trchová, M.; Proke,J.; Varga, M.; Stejskal, J. Electrochimica Acta 2011, 56, 3580 DOI: $10.1016 / \mathrm{j}$. electacta.2010.08.041

27. Khanna, PK.; Singh, N.; Charan S. ; Viswanath, AK. Mater. Chem. Phys. 2005, 92, 214.

DOI: $10.1016 /$ j.matchemphys.2005.01.011

28. Du, J.M.; Liu,Z.M. ; Han,B.X. ; Li, Z.H.; Zhang, J.L. ;Huang, ,Y. Micro Macr. Mater. 2005, 84, 254 DOI: $10.1016 /$ j.micromeso.2005.05.036,

29. Pillalamarri, S.K.; Blum, F.D. ; Tokuliro, A.T. ; Bertino, M.F. Chem. Mater. 2005, 17, 5941.

DOI: $10.1021 / \mathrm{cm} 050827 \mathrm{y}$

30. Shengyu, J.; Shuangxi, X.; , Lianxiang, Y.; , Yan, W.; C, Zhao. Mat. Lett. 2007, 6, 2794. DOI: $10.1016 /$ j.matlet.2006.10.032

31. Stejskal, J.; Trchova, M.; Brozova, L .; Prokes, J.. Chem. Pap. 2009,63, 77 DOI: $10.2478 / \mathrm{s} 11696-008-0086-\mathrm{Z}$

32. Patil, D.S.; Shaikh, J.S.; Pawar, S.A.; Devan, R.S.; Ma,Y.R.; Moholkar ,J.H; Kim, $\quad$ A.V.; $\quad$ Kalubarme, R.S.; Park, C.J.; Patil, P.S. Phys. Chem. Chem. Phys., 2012,14, 11886. DOI: $10.1039 / \mathrm{C} 2 \mathrm{CP} 4175$

33. Ugarte, D.; Roman, L.S.; Aldo, J.G. J. Phys. Chem. B, 2006, 110, 17063.

DOI: $\underline{10.1021 / \mathrm{jp} 060861 \mathrm{f}}$

34. Tiwari, A.; Mishra, A. K.; Kobayashi, H.; Turner, A. P. F. ; Wiley USA, ISBN 978-04-709387-99, 2012; 2 
35. Kargirwar, S.R.; Thakare, S.R.; Choudhary, M.D.; Kondawar, S.B.; Dhakate, S.R. Adv.Mat.Lett. 2010, 2(6), 397. DOI:10.5185/amlett.2011424

36. Kondawar, S. B. ; Agrawal, S. P. ; Nimkar, S. H.; Sharma, H. J. ; Patil , P. T. Adv.Mat.Lett. 2012, 3(5), 393-398 DOI: $10.5185 /$ amlett.2012.6361

37. Shukla,S.K.;Vamakshi.;Minakshi.; Anand,B.; Shekhar,A.; Tiwar,A. Adv. Mat. Lett. 2012, 3(5), 421-425 DOI: $10.5185 /$ amlett.2012.5349

38. Ali, Y.; 1, Kumar, V.; Sonkawade, R. G.; Dhaliwal, A. S. DOI: $10.5185 /$ amlett.2012.6358

39. Street, G.B.; Clarke. T.C.; Geiss, R.H.; Lee, V.Y.; Zazzal, A.P.; Flunger, P.; Scott J.C. J De Physique 1983, 44, 599

40. Arsow, Lj. D.; Plinth, W.; Kobmehl, G. J Sol. Electrochem. 1998, 2,355-361. DOI: $10.1007 / \mathrm{s} 100080050112$

41. Jain, M.; Annapoorni, S. Synth. Met. 2010, 160, 1727. DOI: $10.1016 / j$. synthmet.2010.06.008,

42. Xu,Q.;Leng,J.;Li,H.;Lu,G.;Wang,Y.;Hu,X. Reac. and Func. Polym. $2010,70,663$

DOI: $10.1016 /$ j.reactfunctpolym.2010.05.012.

43. Trchova, M.; Konyushenko, E.N.; Stejskal, J.; Kovarova, J.; Marjanovi, G.C. Polym. Degrad. Stab. 2009, 94, 929.

DOI: $10.1016 /$ j.polymdegradstab.2009.03.001

\section{Advanced Materials Letters}

\section{Publish your article in this journal}

ADVANCED MATERIALS Letters is an international journal published quarterly. The journal is intended to provide top-quality peer-reviewed research papers in the fascinating field of materials science particularly in the area of structure, synthesis and processing, characterization, advanced-state properties, and applications of materials. All articles are indexed on various databases including $\underline{\mathrm{DOAJ}}$ and are available for download for free. The manuscript management system is completely electronic and has fast and fair peer-review process. The journal includes review articles, research articles, notes, letter to editor and short communications. 